\title{
Trabeculectomy in Staphyloma Eye with High Intraocular Pressure Following Ocular Trauma - A Case Report
}

\author{
Masitha Dewi Sari* (iD \\ Department of Ophthalmology, Faculty of Medicine, Universitas Sumatera Utara, Medan, Indonesia
}

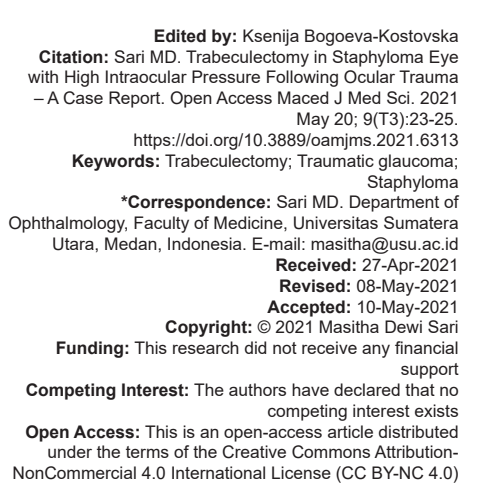

\begin{abstract}
BACKGROUND: Ocular trauma may alter the anterior segment condition that may lead to secondary glaucomas such as inflammation, hyphema, angle recession, and lens subluxation. One of the most common procedures to decrease intraocular pressure (IOP) is trabeculectomy by creating pathways that allow aqueous humor to flow out of the anterior chamber. Scleral tissue destruction can cause damage in thin areas (such as posterior to the rectus muscle insertions) as in case of scleritis.

CASE REPORT: An 11-year-old boy presented to the Ophthalmology Department of Universitas Sumatera Utara Hospital with a bigger white grayish mass and blurry vision. There was a history of the left ocular trauma 6 years ago, followed by redness of the eye, but not treated properly. On the general examination, the patient's left eyes looked cloudy. On ocular examination, the left eye visual acuity was $1 / 300$ and IOP was $28 \mathrm{mmHg}$. Segment anterior examination showed staphyloma from 9 to 12 o'clock, conjunctival injection, corneal scar, shallow anterior chamber, and cloudy lens. We could not asses the posterior segment due to cloudy media. We gave anti-glaucoma medication for 1 month, but the IOP did not decrease. We performed a trabeculectomy to control IOP and to prevent staphyloma from getting bigger.
\end{abstract}

CONCLUSION: Trabeculectomy was an effective procedure to control IOP in a staphyloma eye following ocular trauma.

\section{Introduction}

Staphyloma refers to a localized bulging of the weak and thin outer tunic of the eyeball (cornea or sclera), lined by uveal tissue which shines through the thinned out fibrous coat, then adds its color to the thinned sclera, giving an appearance of bluish to almost black color. Scleral staphylomas are scleral ectasia that is lined internally by uveal tissue. Scleral tissue destruction can cause damage in thin areas (such as posterior to the rectus muscle insertions) as in case of scleritis. In children, staphyloma may occur as a result of long-standing increased intraocular pressure (IOP) or axial myopia, due to the relative distensibility of the sclera in the young [1], [2], [3]. Staphyloma can be classified based on anatomy as anterior staphyloma, intercalary staphyloma, equatorial staphyloma, posterior staphyloma, and peripapillary staphyloma [1], [2], [4], [5].

Ocular trauma may result in secondary glaucoma either by open angle or angle closure. Ocular trauma may alter the anterior segment condition that may lead to secondary glaucomas such as inflammation, hyphema, angle recession, and lens subluxation. If this condition is founded together, it may lead to elevated IOP initially after trauma and if this condition happens for a long time, it may result in glaucomatous optic nerve damage [5], [6]. Moreover, following ocular trauma, angle-closure glaucoma without a pupillary block may develop from the formation of peripheral anterior synechiae associated with angle recession or from contusion, hyphema, and inflammation.

The aim of all glaucoma treatments is lowering IOP to preserve visual function or to improve quality of life. But not effective to everyone, some of them have to take surgical treatment. One of the most common procedures is trabeculectomy. Trabeculectomy also called filtering surgery is a procedure to decrease IOP by surgical corneoscleral with creating pathways that allow aqueous humor to flow out of the anterior chamber.

\section{Case Report}

An 11-year-old boy presented to the Ophthalmology Department of Universitas Sumatera Utara Hospital with a bigger white greyish mass, blurry vision in his left eye (Figure 1). There was a history of the left ocular trauma 6 years ago, followed by redness of the eye, but not treated properly. He got traditional medicine for his left eye instead of proper medication. Then, his eye got worse and cloudier. He was born of 
a full-term normal vaginal delivery, birth weight, and vaccine history was unclear.

On the general examination, VAS score was 4/10, patient's left eyes looked cloudy. On ocular examination, the left eye visual acuity was 1/300 (hand movement) while the right eye was 6/6. And IOP was $28 \mathrm{mmHg}$. Segment anterior examination showed staphyloma from 9 to 12 o'clock, conjunctival injection, corneal scar, shallow anterior chamber, and cloudy lens. We could not asses the posterior segment due to cloudy media. The patient was started on antiglaucoma medication for 1 month (pilocarpine 2\% eye drop 4 times daily, brinzolamide eye drop 3 times daily, and acetazolamide $125 \mathrm{mg}$ peroral 3 times daily) accompanied by antibiotics and steroid (levofloxacin eye drop 4 times daily, and dexamethasone, neomycin sulfate, polymyxin sulfate eye drop 4 times daily, and amoxicillin oral suspension $250 \mathrm{mg}$ peroral 3 times daily).

After 1 month treatment with antiglaucoma, the IOP did not decrease. We performed trabeculectomy with general anesthesia to control IOP and to prevent staphyloma getting bigger (Figure 2). Post-operative patient was given combination steroid and antibiotic eye drop and ointment (tobramycin dexamethasone eye drop 4 times daily; dexamethasone neomycin polymyxin eye ointment twice daily), anticholinergic (homatropine eye drop twice daily), oral antibiotic (cefadroxil $250 \mathrm{mg}$ oral suspension twice daily), and NSAID oral (ibuprofen syrup $3 \times 100 \mathrm{mg}$ ).

One day after trabeculotomy, patient still feels pain in the left eyes, the visual acuity was $1 / 300$, IOP within normal limits. Segment anterior examination showed staphyloma in 9-12 o'clock, close suture at 2
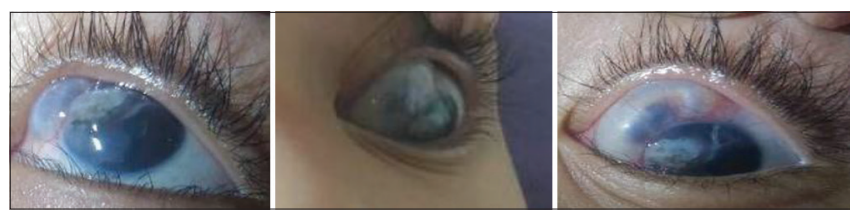

Figure 1: Pre-trabeculectomy o'clock, subconjunctival bleeding, conjunctival injection, corneal leukoma, corneal pannus, normal anterior chamber, and cloudy media (Figure 3 ).

Routine follow-up on day $12^{\text {th }}$ showed minimal pain in the left eye, the visual acuity was $1 / 300$, IOP was $14 \mathrm{mmHg}$. Segment anterior examination showed minimal subconjunctival bleeding, bleb formed, white-grayish mass from 9 to 12 o'clock, corneal leukoma, corneal pannus, normal anterior chamber, and cloudy media.

\section{Discussion}

The most common ocular injuries in the pediatric population are ocular foreign body, sharp object injury, and trauma. All of the ocular traumas need urgent ophthalmology assessment and treatment to prevent morbidity. Cornea erosion most often happened in the ocular trauma and required prompt medication to prevent infection [7], [8].

The prevalence of corneal leukoma and staphyloma in children was $0.03 \%$. More than 2.5 million eye injuries occur each year, often sufferers permanently lose part or all of their vision. Almost 30\% of them are younger than 18 years. In this case, previous ocular trauma may affect the cornea. He got traditional medicine in spite of proper medical treatment and resulted in an unresolved corneal infection and corneal scar. The Formation of corneal opacity or scar is caused by activation and transformation of corneal stromal cells, cytokines, destruction, and remodeling of collagen structure [9], [10].

The most common organisms involved in scleritis are Pseudomonas aeruginosa, Staphylococcus species, Streptococcus species, Stenotrophomonas maltophilia, Serratia marcescens, Mycobacterium species, Haemophilus influenza, Nocardia, virus, and fungus [11]. In this case, untreated corneal infection might spread into
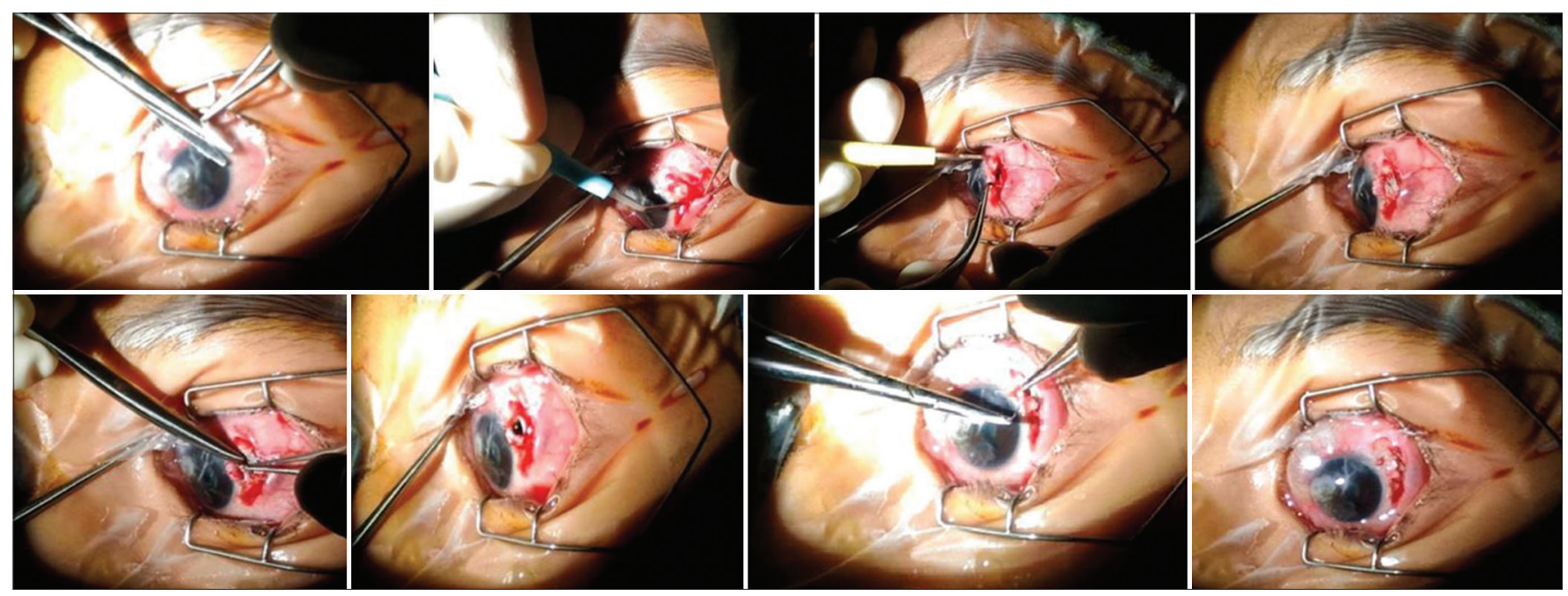

Figure 2: During trabeculectomy 


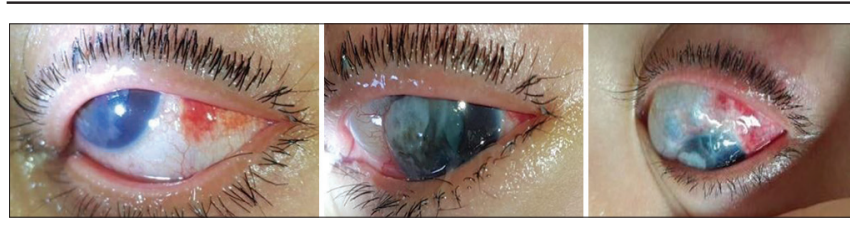

Figure 3: Post-trabeculectomy

adjacent sclera which might lead to necrotizing scleritis and anterior scleral staphyloma. Scleral staphylomas are scleral ectasia that is lined by uveal tissue. Scleral tissue destruction can cause damage in thin areas (such as posterior to the rectus muscle insertions) as in case of scleritis [1]. In this case, anterior scleral staphylomas occurred due to previous trauma and infection that is not treated properly. Then, the scleral wall became thin and weak.

About $4 \%$ of cases following ocular injury can elevate IOP. Post-traumatic glaucoma followed closed globe injuries has contributed as much $77 \%$ and $23 \%$ followed open globe injuries [12]. The aim of all glaucoma treatments is lowering IOP to preserve visual function or to improve quality of life. Medical management consists of prostaglandin analogue, $\beta 2$ adrenergic antagonist, $\alpha 2$ adrenergic agonist, carbonic anhydrase inhibitor, parasympathomimetic agents, and hyperosmotic agents [6]. We treated this patient using pilocarpine eye drop (parasympathomimetic), brinzolamide eye drop (topical carbonic anhydrase inhibitor), and acetazolamide eye drop (oral carbonic anhydrase inhibitor) for $1 \frac{1}{2}$ months, but the IOP did not decrease to normal level.

Trabeculectomy also called filtering surgery is a procedure to decrease IOP by surgical corneoscleral with creating pathways that allow aqueous humor to flow out of the anterior chamber [6]. The indication of trabeculectomy in this case is uncontrolled IOP despite having maximal antiglaucoma medication.

The efficacy of trabeculectomy was as high as $65 \%$ [13], [14]. We performed trabeculectomy as usual except that we made a conjunctival incision at 12-3 o'clock. Usually, we made a conjunctival incision at 10-2 o'clock but we could not do it because of staphyloma [6]. Trabeculectomy modification such as using antifibrotic agent can improve trabeculectomy efficacy in decreasing IOP [6]. However, in this case, we did not use antifibrotic agent because the sclera was already thin and may impair the sclera. We were successful in lowering the IOP from $28 \mathrm{mmHg}$ to $14 \mathrm{mmHg}$ in this case. The bleb was seen on the $3^{\text {rd }}$ day after the trabeculectomy, and the boy did not complain about the headache anymore.

\section{Conclusion}

Trabeculectomy is one of indications in case of uncontrolled IOP despite having maximal antiglaucoma therapy. In this patient, trabeculectomy is not only to control IOP but also to prevent staphyloma enlarging.
Hence, trabeculectomy was effective in controlling IOP in staphyloma eye following ocular trauma.

\section{References}

1. Rosa RH. Ophthalmic Pathology and Intraocular Tumor. $4^{\text {th }}$ ed San Fransisco: American Academy of Ophthalmology; 20192020. p. 145-6.

2. Khurana AK, Khurana BP. Comprehensive Ophthalmology: Disease of Sclera. $7^{\text {th }}$ ed. New Delhi: Jaypee Brothers Medical Publisher; 2018. p. 149-50.

3. Eva-Riordan P, Ausburger JJ. Vaughan and Asbury's General Ophthalmology. Uveal Tract and Slera. $19^{\text {th }}$ ed. Glashütte, Germany: Lange; 2018. p. 383-4.

4. Wiesenthal RW. External Diseases and Cornea. $8^{\text {th }}$ ed. San Fransisco: American Academy of Ophthalmology; 2019-2020. p. 372-4.

5. Salmon JF. Clinical ophthalmology a systematic approach. In: Kanski's: Degenerative Myopia, Dome Shaped Macula, Congenital Optic Disc Anomaly, Trabeculectomy. $9^{\text {th }}$ ed. Amsterdam, Netherlands: Elsevier; 2020. p. 412-9, 604, 612, 778-80.

6. American Academy of Ophthalmology. Glaucoma. $10^{\text {th }}$ ed. San Fransisco: American Academy of Ophthalmology; 2019-2020. p. 131-7, 175.

7. Pi LH, Chen L, Liu Q, Ke N, Fang J, Zhang S, et al. Prevalence of eye diseases and causes of visual impairment in schoolaged children in Western China. J Epidemiol. 2012;22(1):37-44. https://doi.org/10.2188/jea.je20110063

PMid:22123227

8. Cohen N, Cohen E, Anafy A, Margaliot A, Kaganov K, Gomel N, et al. Predictors of traumatic eye injuries at high-risk for ophthalmic complications in children. Eur J Pediatr. 2021;180(1):177-85. https://doi.org/10.1007/s00431-020-03734-0

PMid:32642855

9. Sitompul R, Kusumowidagdo G, Matiur EB, Barliana JD, Sitorus RS, Sungkar S. Post-ocular trauma corneal staphyloma in a child living in an underdeveloped region of Eastern Indonesia. Case Rep Ophthalmol. 2018;9(1):24-9. https://doi.org/10.1159/000485553 PMid:29681830

10. Zhou Y, Chen Y, Wang S, Qin F, Wang L. MSCs helped reduce scarring in the cornea after fungal infection when combined with anti-fungal treatment. BMC Ophthalmol. 2019;19(1):226. https:// doi.org/10.1186/s12886-019-1235-6

PMid:31727008

11. Reddy JC, Murthy SI, Reddy AK, Garg P. Risk factors and clinical outcomes of bacterial and fungal scleritis at a tertiary eye care hospital. Middle East Afr J Ophthalmol. 2015;22(2):203-11. https://doi.org/10.4103/0974-9233.150634

PMid:25949079

12. De Leon-Ortega JE, Girkin CA. Ocular trauma-related glaucoma. Ophthalmol Clin North Am. 2002;15(2):215-23. PMid:12229238

13. Ranjan A, Rao A. Ahmed glaucoma valve surgery for necrotizing scleritis with secondary glaucoma. Int Ophthalmol. 2014;34(2):327-9. https://doi.org/10.1007/s10792-013-9782-y PMid:23636673

14. Wagner FM, SchusterAK, Emmerich J, Chronopoulos P, Hoffmann EM. Efficacy and safety of $X E N \circledast$-Implantation vs. trabeculectomy: Data of a "real-world" setting. PLoS One. 2020;15(4):e0231614. https://doi.org/10.1371/journal.pone.0231614

PMid:32310972 